\title{
On the Construction of Smart Classroom in Shanghai JiaoTong University
}

\author{
Shen Hongxing, Shao Jingjing \\ Educational Technology Center, Shanghai JiaoTong University, Shanghai, China \\ Email address: \\ hxshen@sjtu.edu.cn (Shen Hongxing), shaojj@sjtu.edu.cn (Shao Jingjing)
}

\section{To cite this article:}

Shen Hongxing, Shao Jingjing. On the Construction of Smart Classroom in Shanghai JiaoTong University. Higher Education Research. Vol. 5, No. 4, 2020, pp. 137-142. doi: 10.11648/j.her.20200504.14

Received: April 30, 2020; Accepted: May 29, 2020; Published: June 28, 2020

\begin{abstract}
The integration of information technology and teaching puts forward new demands on the teaching environment of colleges and universities, which further drives the reform. How to construct the intelligent teaching environment in colleges and universities in a scientific and reasonable way so as to provide high quality resources, places and facilities for promoting the cultivation of innovative and compound talents? Based on the existing problems of teaching facilities and environment in colleges and universities as well as the needs of transformation, this paper expounds the connotation, construction objectives and contents of intelligent teaching environment, analyzes and explores the construction and application of intelligent teaching environment from eight aspects, and analyzes some controversial issues in the construction of intelligent teaching environment. Wisdom for the construction of the teaching environment to create good teaching and learning space, provide multiple technology facilities and means of teaching, strengthen the construction of teaching resources, to provide online and offline to seamlessly combine the teaching process of services, and promote the education teaching reform, in the process of the development of education informationization deepening constantly advancing with The Times in the practical work experience and thinking is analyzed, in order to play a role of reference for teaching reform.
\end{abstract}

Keywords: Smart Classroom, Online Teaching Platform, Classroom Intelligent Interactive System, Normal Recording and Broadcasting, Multi-screen Display System

\section{Current Common Problems}

The era of educational informatization 2.0 has given birth to the continuous changes in teaching methods and means. The deep integration of information technology and teaching has put forward new requirements for the classrooms of colleges and universities, which further promote new changes. How to construct the intelligent classroom scientifically and reasonably, and to provide high-quality resources, places and facilities to promote the cultivation of innovative and compound talents, has become an important topic of the hardware construction of modern-day universities in the new era. [1]

Before building a smart classroom, it is necessary for us to analyze what problems exist in the current college classroom. After investigation and research, the author found that the following problems are common in most colleges and Universities:

\subsection{Teaching Facilities Cannot Meet the Needs of Teaching in the Information Age}

Teachers basically adopt the traditional teaching method of blackboard writing + PPT, with single methods and means; the classroom lacks information technology facilities such as supporting attendance statistics, classroom answering, group discussion, online live broadcast, wireless screen casting, etc., so teachers cannot use the new teaching methods to teach; In some colleges multimedia equipment have low configuration and long service life, and thus students cannot even see and hear clearly in the classroom. It seriously affects the teaching result.

\subsection{Lack of Interaction in Class}

The teaching method of teachers is too traditional, focusing on lecturing. In the end, there is a general lack of interaction between teachers and students, students and students, lack of 
ideological exchange, let alone critical thinking.

\subsection{The Teaching Building Environment Is Not Appealing}

It is mainly reflected in the poor decoration of the teaching building, the monotonous and simple environment, the lack of study space, and the lack of suitable places for teachers and students to communicate. Seats are densely installed in the classroom, to the extent that the actual personal area per student is less than 0.5 square meters. Considering the fact that the post-90s students are generally taller, these classrooms are obviously crowded. The desks and chairs in the classroom are also generally fixed in rows, unable to be moved around, and fail to provide the physical conditions for group interactive discussion. Teaching buildings generally lack cultural atmosphere.

\subsection{The Size of Classroom Does Not Adapt to the Teaching Reform}

The classroom area does not match the size (number of people) of the teaching class. The university classroom is generally built according to the teaching needs of the 1980 s and 1990s, and the area is mainly medium-sized and large-scale. However, in recent years, the teaching reform has profoundly affected the methods of college teaching, and the proportion of small class teaching has been increasing year by year. As a result, a considerable number of small class are arranged in the classroom with more than 100 seats, resulting in "small class and large classroom" In the face of the empty classroom, teachers have poor experience in class. On the other hand, there is a waste of classroom resources.

Presented with the above problems, the school should carry out transformation, and build a modern teaching building with beautiful environment, class seat activities, advanced technical facilities and off-duty space to meet the development trend of future intelligent teaching. Based on these problems, this paper discusses the connotation of smart classroom, and analyzes and explores the construction and application of smart classroom from eight aspects.

\section{What Is a Smart Classroom}

\subsection{Definition of Smart Classroom}

Under the guidance of pedagogy theory, smart classroom is the optimization and reconstruction of the physical teaching space, teaching software and hardware facilities by using information communication, big data, artificial intelligence and other technologies [2], so that it has the functions of perception record, intelligent control, convenient use, interactive real-time, data collection, analysis and feedback, so as to improve the effectiveness of teaching and learning. Smart classroom is a smart school an important part of the garden. [3]

\subsection{Construction Objectives of Smart Classroom}

The construction goal of smart classroom has four aspects, which are teach, learn, evaluate and manage. The teaching of smart refers to the empowerment of teachers that they are able carry out a variety of teaching modes by utilizing the smart classroom [4] and teaching technology; the learning of smart refers to the provision of learning resources and learning space for enhancing study performance of the students; the evaluation of smart refers to the ability to record, analyze and provide objective evaluation of the teaching process of teachers and the learning process of the students; [5] the management of smart refers to the easy management of teaching facilities, teaching process and teaching results from the perspect of teaching managers. [6]

\subsection{Construction Ideas of Smart Classroom}

The construction of the smart classroom should be learner-centered. The content of it [7] includes comfortable teaching building space, movable desks and chairs for discussion between teachers and students, and technical facilities that can support multiple teaching modes. [8]

The creation of the space environment of teaching buildings should be practical, simple, quiet and comfortable and based on people-oriented principle. The buildings should be energy-saving, environmentally friendly, and lighted with natural or soft light source. The buildings should maintain natural ventilation as much as possible, and equipped with air conditioning (recommended ceiling), ventilation device, intelligent monitoring and air quality regulation. The color matching should be appropriate. The desks and chairs should be comfortable, flexible, safe and environmentally friendly that is comply with ergonomics; the teaching building should has public reading space, which carries the construction of campus culture and embodies humanistic care.

The smart classroom should support the innovative teaching mode. The facilities should be equipped with software and hardware. The construction of a smart classroom should involve a physical classroom and a matching online virtual classroom. It can integrate the online and offline teaching, so as to extend the time and space of teaching and learning, and to enable the educational innovation with technology.

\section{The Construction and Application of Smart Classroom}

This paper takes the construction of smart classroom of Shanghai JiaoTong University as an example to build and apply the concept of smart classrooms in eight aspects.

\subsection{High Quality Multimedia Audio-visual Facilities}

Multimedia audio-visual facilities are the infrastructure of the smart classroom. A smart classroom should be equipped with high-quality display system and audio system to ensure that students can see and hear the class content clearly. Generally speaking, intelligent interactive flat panel integrated machine should be used in small classroom, and high-definition laser ultra-short focus projector should be used 
in middle-sized classroom. Considering that large screen is used in large classroom, the projection light may reflect on the teacher's face, so it is not suitable to be equipped with laser projector; instead high-definition and high-definition bulb projector is recommended.] Digital writing screen can be synchronously enlarged and displayed, and blackboard writing can be saved. It supports dual screen PPT asynchronous display, which is convenient for students to watch the content of PPT before and after, and keep the continuous listening ideas.

For the audio system, in order to ensure the students can hear lectures clearly, we need to pay special attention to the reverberation time of the classroom. Many of the reverberation time of the classroom exceeds well over the standard, resulting in the poor definition of the amplification and the poor pickup effect of the recording and broadcasting equipment. The reverberation time of smart classroom should be in the range of 0.7-1.2 seconds, varying upon different volume. [9] Teachers' voice should have enough volume, high definition and high reduction through wireless microphone and multimedia amplification, while sound image remain the same.

\subsection{Classroom Intelligent Interactive System}

Classroom intelligent interactive system (also known as voting interactive system or real-time feedback interactive system) uses mobile phones or mobile terminals to interact in the classroom. Teachers arrange exercises and test questions in the classroom. Students answer and submit questions in real time. The system automatically counts the answer results, generates scores and feeds the answer results back to the screen in real time. Teachers can manage pacing of teaching in time by adjusting the teaching rhythm or strategy according to the feedback. All the answer data are saved in the server synchronously, so that students can do the review and the faculty can conduct data analysis later. [10]

The author conducted a questionnaire survey on the effectiveness of classroom intelligent interaction system used by students in our school, and collected 341 questionnaires in total. Generally speaking, students agree that classroom intelligent interaction system has a positive effect on activating classroom atmosphere, enhancing interaction between teachers and students, mastering learning content, and on many other aspects. Students' satisfaction is more than half. Some students call voting terminal as classroom artifact.

\subsection{Normal Classroom Recording and Broadcasting System}

The normal recording and broadcasting can record the teacher's lecture, PPT, blackboard writing and other information in the daily classroom for the students to review after class. Technically, the recording and broadcasting classroom is equipped with EPTZ $4 \mathrm{~K}$ high-definition camera. The course recording system is connected with the course schedule, which can perform three important kinds of automations: automated recording based on course schedule, automated camera tracking according to movement the teacher, and automated upload of course videos to the resource platform or online learning platform. Thanks to the development of cloud architecture, maintenance cost of the system is lower, allowing it to be more applicable for slarge-scale deployment [11].

The recording and broadcasting system has the function of remote classroom, which allows synchronous teaching between campuses in eastern and western regions, and international cooperation. Students can $\log$ in and join the classroom individually to utilize the sharing and balanced development of educational resources. New teachers can recognize the shortcomings in their teaching and improve the teaching methods and thus the teaching result by watching the classroom video,

\subsection{Online Teaching Platform (LMS)}

The offline smart classroom provides a solution to the problems that our teaching communities are facing in classroom, but it can't support the teaching process outside the classroom, In order to allow teaching activity to happen before and after class, an online teaching platform is required. On the online teaching platform, we set up a great amount of virtual network spaces of teaching classes, which are mapped with the offline classroom teaching classes one by one, and the network space is also based on the teaching classes For the existence of units, the interaction between teachers and students is conducted in the same way like they do in classroom. Teachers can release learning materials such as notices, assignments and tests on the platform. Students can submit assignments, answer questions, group discussions and peer reviews online.

The online teaching platform is seamlessly connected with the offline smart classroom in multiple ways. The system integrates the online and offline classrooms, provides solutions for classroom teaching, hybrid teaching, flipped classroom and other teaching forms and teaching processes. The behavior data of teachers and students on the online teaching platform are recorded on the server. School administrators can analyze these data, form personalized data reports of teachers' teaching and students' learning, and generate feedbacks based on the data, and help teachers and students to improve the result of higher education.

\subsection{Multi-screen Display System}

The multi-screen display system has several screens for group discussion class. In group discussion classes, the students are divided into groups of 5-8, each group equipped with a display screen. First the teacher gives lectures, then the students discuss, and before the class ends each group sends a representative to share insights. From the perspective of facilities and functions, matrix support is needed, dealing with the three above working states: when the teacher is giving a lecture, all screens display the teacher's content; when the group is discussing, each group's electronic screens display its own group's content; when the group representative is speaking, all screens display the content on the group's screen 
The system also supports wireless sharing and asynchronous display.

The multi-screen display system allows the flipped classroom teaching mode to be applied and promotes the communication and learning in small groups, which is a hot topic in the construction of innovative teaching in the teaching reform.

\subsection{Intelligent Teaching Evaluation System}

The intelligent teaching evaluation system includes online supervision system, student evaluation system and student learning evaluation system. the intelligent teaching evaluation system collects student data in the teaching process, including pre class student preview time, discussion times, attendance of middle school students in the class, student listening state, interaction between teachers and students, accuracy rate of student's answer, teacher's class state, student's evaluation score, after class students' homework completion, students' questions and discussions, students' accuracy rate of answering questions, and teachers' answer times.

The video and audio system of standardized examination room and cloud recording and broadcasting system can be easily be modified and expanded into online teaching supervision system, which can be used for online school lectures and teaching order management. Supervisors can watch teachers' lectures and students' lectures online, and give online grading suggestions. On the one hand, they can monitor the teaching quality, find out the problems in school teaching work in time, on the other hand, they can help teachers improve their teaching skills according to the problems of teachers. By applying image intelligence algorithms, they can calculate the number of people in the teaching room, so that they can collect the attendance rate of each teaching class.

\subsection{Intelligent Control and Operation and Maintenance System}

The best way to manage the smart classroom is called smart management, which gives birth to the intelligent control and operation and maintenance management system (ERP). The system can automatically switch on and off multimedia facilities according to the timetable, classroom lightings according to the illumination, air conditionings according to the temperature and humidity, ventilation devices according to the concentration of $\mathrm{CO}_{2}$. The system can be manually controlled by the teacher, one key to class, one key to class. If necessary, the system can be remote controlled and managed by the staff; the system is set up with a variety of classroom modes to facilitate the teacher's signal switching It collects and analyzes data such as classroom equipment failure, energy consumption, air quality. It will automatically alarm when the number goes beyond set range.

The purpose of ERP operation and maintenance system of classroom management is to promote the standardization and work flow of operation and maintenance, and improve the quality of the service. The platform function includes centralized control of multimedia facilities, troubleshooting, patrol and clock in, help-seeking service, work log recording and other matters. The workflow is managed in the form of work order. IP phone is installed on the classroom platform to meet the needs of teachers. Pressing any key, the teacher in need is connected to the service duty room and thus can talk with the operation and maintenance personnel of the multimedia teaching system.

\subsection{Data Analysis and Visual Display System}

The data visualization release system aims to release information that reflects the status of classroom like classroom configuration, use, curriculum, number of people, temperature through large screens, electronic class boards and other digital facilities. Teachers and students can thus understand the information of the teaching building in time, and the management personnel can grasp the operation status of the teaching building in a timely manner and provide data basis for the best operation of the classroom all the time.

By adopting the above data display and analysis methods, we are now able to get the corresponding evaluation results and push it both to students to promote their personalized learning, and to teachers to adjust their teaching strategies. School managers can utilize the data to promote the precise implementation of policies as well.

\section{Hot Topics}

Many new technologies have been adopted in the construction of smart classroom, and most of them have did a very good job, but there are still some topics remained in heated debate. Developed upon practical experience and personal understanding, the author wants to share following reflections with and hopefully bring some insights to the community.

\subsection{Shall We Install Monitoring and Recording Devices in the Classroom}

The installation of monitoring and recording equipment in the classroom is the necessary answer to the demand of data collection in the teaching process. After all, the classroom is a public space rather than a private place. The installation monitoring of the classroom plays an important role in the standardized management of safe campus, honest examination, teaching behavior.

The recording and broadcasting video and audio data is an important means of education resource construction. Through the automatic recording and broadcasting equipment, teachers' videos in the classroom are recorded and contribute to build up an important teaching video resource library of the school. Teachers can reflect and improve the teaching through the course video, students can learn through video on demand before and after class, and have a better grasp of knowledge points. The construction of video resources promotes the recording and sharing of high-quality resources, which are significantly helpful to the professional development of teachers and the improvement of students' studies. 
A small number of teachers and students have concerns about monitoring and recording on privacy issues. Thus the relevant departments had accordingly put out stricter policies on management of the video to erase the concerns of teachers and students.

\subsection{Is the System of Face Recognition, Behavior and Expression Cited}

Following the trend of implementing cutting edge technologies like face recognition and behavior discrimination, a lot schools also put expression discrimination systems into trial, but the implementation also brought up new contradiction between providing convenience and protecting personal privacy is increasingly prominent, and caused a lot of disputes. Technology is a surely double-edged sword. The application of technology is not suppose to cause negative effects or stress on most teachers and students. In view of the fact that many teachers and students were reluctant to accept face recognition devices, and especially considering that the accuracy of expression design system is also controversial, the author does not recommend these systems to be widely used in classroom teaching for the time being, before some experimental tests are done.

\subsection{Shall Mobile Phones Be Allowed in the Classroom to Be Served as Terminals}

Some teachers think that mobile phones, iPads and other mobile terminals have too many functions, and would inevitably students from the class, so they don't allow students to use them in class. In the smart classroom, however, the introduction of mobile terminals for classroom teaching stimulates classroom interaction motivates the participation of students, and organically combines teachers' teaching methods. Timely feedback to the students to help students concentrate on their learnings and cultivate students' ability of independent learning. In the future, more and more terminal applications will appear in the classroom. The application of mobile terminals is a inevitably trend in higher level education.

\subsection{Is Multi-screen System Necessary in Every Smart Classrooms}

The multi-screen system is conducive to the development of new teaching mode, but it is difficult to operate and manage, and many teachers are not accustomed to it, so the utilization rate of the multi-screen system is rather low. Considering the large investment, it is not economic to install the system in every smart classroom. Only a small part of the classrooms need the installation as long as they meet the demand.

\subsection{Shall We Keep the Blackboard}

Blackboard, as a traditional classroom teaching equipment, plays an important role in traditional teaching methods. But nowadays, interactive whiteboard, electronic blackboard and other teaching products have become the more popular equipment of intelligent classroom teaching. Is blackboard replaceable? The author conducted a survey in our school. The result shows that, about $15 \%$ of the classes have got rid of blackboard, $35 \%$ of the classes rarely use blackboard, $30 \%$ of the classes use blackboard from time to time, and $20 \%$ of the classes are fully relied on blackboard. During the survey, most of the teachers think that blackboard should not be removed. Some subjects, especially those in which the display of formula calculations and derivations is essential, such as mathematics and physics, have a strong demand for blackboards.

\subsection{Is Electronic Class Cards Necessary}

Electronic class sign has a variety of functions like identity identification, attendance, access control unlocking, notice announcement, information query and classroom status information. But, in practical use this kind of equipment has not been used effectively in colleges and universities, and has become merely a decoration. The excessive configuration of equipment causes waste of resources.

\section{Conclusion}

The construction of smart classroom in Colleges and universities creates an interactive teaching and learning space, provides multiple teaching technology facilities and means, strengthens the construction of teaching resources combines online and offline teaching services in a seamless manner, and thus promotes the reform of education and teaching to achieve the fundamental goal of talent development. This paper is a personal take generated upon author's own experience, with a hope of providing some insights to the teaching reform in colleges and universities.

\section{References}

[1] Using the interactive white board in teaching and learning - an evaluation of the smart classroom pilot project [J]. Interdisciplinary journal of e-skills and lifelong learning, 2011, 7 (in print): 191-198.

[2] Li Suna. Improving the innovation ability of college students with intelligent education [J]. Education modernization, 2017, 4 (37): $35-36$

[3] Yang Xianmin, Liu Yongqian, Zhong Xiaoliu, et al. China's smart education development strategy and path selection $[\mathrm{J}]$. Modern education technology, 2014 (01): 13-20.

[4] Zhong Xiaoliu, Li Haixia, Du Jing, et al. Interpretation of multimedia teaching environment standard [J]. Audio visual education research, 2013, 034 (009): 62-65, 71.

[5] Cui Yaqiang, Yu Qi, Feng niaodong. On the lack of "wisdom" in the intelligent teaching environment of colleges and universities [J]. China education informatization, 000 (013): $\mathrm{p}$. $72-74$.

[6] Zhang Jiping. Learner centered: future classroom environment construction [J]. Primary and secondary school management, 2018, no. 329 (04): 7-9. 
[7] Shen Hongxing. Innovation and practice of educational technology work in Colleges and universities in the era of educational informatization $2.0[\mathrm{~J}]$. Experiment.

[8] Shen Hongxing. Innovation and practice of educational technology work in Colleges and universities in the era of educational informatization $2.0[\mathrm{~J}]$. Laboratory research and exploration, 2019, 038 (006): 128-132.

[9] Wang Jing. Research on the construction of regional education resource sharing based on intelligent education cloud platform [J]. Education modernization, 2018, 5 (22): 119-121149.

[10] GB/T36447-2018 multimedia teaching environment design requirements.

[11] Shen Hongxing. Application of EPTZ intelligent tracking camera in cloud recording and broadcasting $[\mathrm{J}]$. Journal of
Guangxi Radio and Television University (2): 5-9, 5 pages in total.

[12] Shao Jingjing, he Qing, Hao Dakui. Classification, comparison and application of classroom interactive feedback technology: a case study of Shanghai JiaoTong University [J]. Modern education technology (11): 111-116.

[13] Ren youqun. Innovative education calls for educational innovation [J]. Open education research, 2016, 22 (1): 8-9.

[14] Ren youqun. "college talent training reform under mooc." China higher education 000.007 (2014): 26-30.

[15] Yang zong-kai, Yang hao, wu di. On the deep integration of information technology and contemporary education [J]. Education research, 2014, 035 (003): 88-95. 